\title{
The French seismic CATalogue (FCAT-17)
}

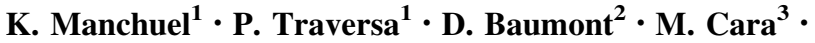 \\ E. Nayman ${ }^{1}$ C. Durouchoux ${ }^{1}$
}

Received: 19 October 2016/Accepted: 12 September 2017/Published online: 23 September 2017

(C) The Author(s) 2017. This article is an open access publication

\begin{abstract}
In regions that undergo low deformation rates, as is the case for metropolitan France (i.e. the part of France in Europe), the use of historical seismicity, in addition to instrumental data, is necessary when dealing with seismic hazard assessment. This paper presents the strategy adopted to develop a parametric earthquake catalogue using moment magnitude $\mathrm{M}_{\mathrm{w}}$, as the reference magnitude scale to cover both instrumental and historical periods for metropolitan France. Work performed within the framework of the SiHex (SIsmicité de l'HEXagone) (Cara et al. Bull Soc Géol Fr 186:3-19, 2015. doi:10.2113/ qssqfbull.186.1.3) and SIGMA (SeIsmic Ground Motion Assessment; EDF-CEA-AREVAENEL) projects, respectively on instrumental and historical earthquakes, have been combined to produce the French seismic CATalogue, version 2017 (FCAT-17). The SiHex catalogue is composed of $\sim 40,000$ natural earthquakes, for which the hypocentral location and $\mathbf{M}_{\mathrm{w}}$ magnitude are given. In the frame of the SIGMA research program, an integrated study has been realized on historical seismicity from intensity prediction equations (IPE) calibration in $\mathrm{M}_{\mathrm{w}}$ detailed in Baumont et al. (submitted) companion paper to their application to earthquakes of the SISFRANCE macroseismic database (BRGM, EDF, IRSN), through a dedicated strategy developed by Traversa et al. (Bull Earthq Eng, 2017. doi:10. 1007/s10518-017-0178-7) companion paper, to compute their $\mathbf{M}_{\mathrm{w}}$ magnitude and depth. Macroseismic data and epicentral location and intensity used both in IPE calibration and inversion process, are those of SISFRANCE without any revision. The inversion process allows the main macroseismic field specificities reported by SISFRANCE to be taken into
\end{abstract}

Electronic supplementary material The online version of this article (doi:10.1007/s10518-017-0236-1) contains supplementary material, which is available to authorized users.

K. Manchuel

kevin.manchuel@edf.fr

1 EDF-DIPNN-CEIDRE-TEGG, 905 avenue du Camp de Menthe, 13097 Aix en Provence Cedex 02, France

2 FUGRO-GEOTER, 03 rue Jean Monnet, 34830 Clapiers, France

3 EOST, UMR 7516, Université de Strasbourg, 5 rue R. Descartes, 67084 Strasbourg Cedex, France 
account with an exploration tree approach. It also allows capturing the epistemic uncertainties associated with macroseismic data and to IPEs selection. For events that exhibit a poorly constrained macroseismic field (mainly old, cross border or off-shore earthquakes), joint inversion of $\mathrm{M}_{\mathrm{w}}$ and depth is not possible, and depth needs to be fixed to calculate $\mathrm{M}_{\mathrm{w}}$. Regional a priori depths have been defined for this purpose based on analysis of earthquakes with a well constrained macroseismic field where joint inversion of $\mathrm{M}_{\mathrm{w}}$ and depth is possible. As a result, $27 \%$ of SISFRANCE earthquake seismological parameters have been jointly inverted and for the other $73 \% \mathrm{M}_{\mathrm{w}}$ has been calculated assuming a priori depths. The FCAT-17 catalogue is composed of the SIGMA historical parametric catalogue (magnitude range between 3.5 up to 7.0), covering from AD463 to 1965, and of the SiHex instrumental one, extending from 1965 to 2009. Historical part of the catalogue results from an automatic inversion of SISFRANCE data. A quality index is estimated for each historical earthquake according to the way the events are processed. All magnitudes are given in $\mathrm{M}_{\mathrm{w}}$ which makes this catalogue directly usable as an input for probabilistic or deterministic seismic hazard studies. Uncertainties on magnitudes and depths are provided for historical earthquakes following calculation scheme presented in Traversa et al. (2017). Uncertainties on magnitudes for instrumental events are from Cara et al. (J Seismol 21:551-565, 2017. doi:10.1007/s10950-016-9617-1).

Keywords Seismic catalogue - Metropolitan France - Seismic hazard · Historical seismicity $\cdot$ Instrumental seismicity $\cdot$ Macroseismicity $\cdot \mathrm{M}_{\mathrm{w}}$ magnitudes

\section{Introduction}

Estimating the characteristics of past earthquakes in terms of location and magnitude are of primary interest for seismic hazard studies, either performed through a probabilistic or a deterministic approach. Indeed, the seismological parameters reported in the parametric earthquake catalogue are used at different stages of seismic hazard assessment studies. They are for example used (i) when establishing seismotectonic zonation and computing recurrence models, (ii) as input for ground motion prediction equations (GMPEs) or (iii) when establishing maximum magnitude $\left(\mathrm{M}_{\max }\right)$ estimates.

Metropolitan France belongs to the western European intraplate domain and behaves as a rigid block characterized by low internal deformation rates (Nocquet and Calais 2004; Walpersdorf et al. 2006). In such a context, characterized by low to moderate seismic activity, it is essential to consider historical seismicity, in addition to the instrumental one when performing seismic hazard assessment studies. This allows to extend the seismological observation time window and consequently to be more representative of the seismogenic behavior of geological structures. Until now, France has suffered, for seismic hazard assessment, from the lack of a homogeneous seismicity catalogue that covers both the instrumental and historical periods.

At national or regional scales, various instrumental earthquake catalogues are available, built and maintained by the seismological observatories. As a consequence, end-users experience difficulties when selecting or concatenating seismicity catalogues for seismic hazard studies. In addition, magnitude conversions need to be applied to obtain a homogenized $\mathrm{M}_{\mathrm{w}}$ catalogue, since most Ground Motion Prediction Equations (GMPEs) are expressed as function of $\mathrm{M}_{\mathrm{w}}$ magnitude. Applying conversion equations leads to increased uncertainties in the seismic hazard studies. 
The objective of the SiHex project (2009-2014) was to produce a catalogue of instrumental seismicity for metropolitan France with accurate hypocenter locations and moment magnitude determinations (Cara et al. 2015, 2017; Denieul et al. 2015). It was jointly instigated by the Bureau Central Sismologique Français (CNRS-University/BCSF) and the Laboratoire de Détection et de Géophysique (CEA-DAM/LDG), and took into account the contributions of the various seismological networks and observatories in France and surroundings countries (Cara et al. 2015). The SiHex catalogue version 2014 (Cara et al. 2015; www.franceseisme.fr) provides the hypocentral location and moment magnitudes $\mathbf{M}_{\mathrm{w}}$ for about 40,000 natural seismic events for the period 1962-2009.

Concerning historical seismicity, our reference is the SISFRANCE macroseismic database (BRGM-EDF-IRSN; www.sisfrance.net), where 100,000 Intensity Data Points (IDPs), associated to $\sim 6000$ earthquakes (463-2007) have been gathered. The assignment of the intensity values to localities is performed by analyzing original documents describing the effects of the earthquakes at those locations. $M_{w}$ estimates for 333 events of the SISFRANCE database are provided in the SHARE (seismic hazard harmonization in Europe) European Earthquake Catalogue (SHEEC-1000-1899) (Stucchi et al. 2012), computed as a weighted average of $\mathrm{M}_{\mathrm{w}}$ estimates coming from SHARE and from the French Parametric Earthquake Catalogue (FPEC) (Baumont and Scotti 2011), with a weight of 25 and $75 \%$ respectively. One of the main objectives of the SIGMA project is to reassess seismological parameters for all the events belonging to the SISFRANCE database. To fulfill this objective (i) IPEs have been calibrated (Baumont et al. submitted), based on the SISFRANCE macroseismic database and $\mathrm{M}_{\mathrm{w}}$ magnitudes provided by the SiHex catalogue (Cara et al. 2015) and by the study of 15 early instrumental large events (1905-1972) in France or abroad close to the boundaries (Benjumea et al. 2015). Then, (ii) $\mathrm{M}_{\mathrm{w}}$ magnitudes, depth and associated uncertainties are computed for all events of the SISFRANCE database through a dedicated inversion scheme (Traversa et al. 2017).

The aim of this paper is to present the French seismic CATalogue (FCAT-17) that combines the SiHex instrumental catalogue and the seismological parameters estimates for historical earthquakes coming from SIGMA works. Firstly, the SiHex instrumental catalogue is briefly presented for reminding. Then, the approach allowing to compute the seismological parameters of historical events is detailed. It includes the processing of the SISFRANCE macroseismic data, the use of the EMPEs developed by (Baumont et al. submitted) within the inversion scheme proposed by (Traversa et al. 2017) and the concatenation with the instrumental period. The FCAT-17 catalogue is provided in a table (Excel format) as supplementary material.

\section{The instrumental SiHex catalogue (1962-2009)}

The instrumental part of the FCAT-17 catalogue is composed of the SiHex catalogue version 2014 (Cara et al. 2015). This section aims at presenting a brief summary of approaches and results carried out in the framework of the SiHex project, which resulted in the instrumental catalogue. Refer to the original papers published by the SiHex teams for more details on this work: Cara et al. $(2015,2017)$ and Denieul et al. (2015).

To determine earthquake locations of French and cross-border earthquakes, arrival times data coming from laboratories and observatories in both France and adjacent countries were retrieved. A single and homogenous 1-D location process has been applied to produce the so-called backbone catalogue (Cara et al. 2015), composed of more than 
40,000 natural events (particular attention has been paid to the discrimination between natural and artificial events). Events location derived from regional observatories were preferred for events in the French Alps, the southernmost Alps and the Mediterranean domain including Corsica, the Pyrenees and the Armorican Massif. These have been substituted in the backbone catalogue solutions (see Cara et al. 2015 for regions boundaries and Fig. 3 for those of Alps, Pyrenees and Armorican Massif).

Moment magnitudes $\mathrm{M}_{\mathrm{w}}$ are calculated from a coda-wave analysis using the LDG seismograms for most $\mathrm{M}_{\mathrm{L}-\mathrm{LDG}}>4$ events (Denieul 2014; Denieul et al. 2015). For smaller magnitude events, $\mathbf{M}_{\mathrm{w}}$ are converted from local magnitudes (Cara et al. 2015, 2017; Denieul et al. 2015). Two different conversion relationships are used according to $\mathrm{M}_{\mathrm{L}}$ - LDG magnitude ranges:

$$
\begin{gathered}
\mathrm{M}_{\mathrm{w}}=\mathrm{M}_{\mathrm{L}-\mathrm{LDG}}-0.6 \text { for } 3.1 \leq \mathrm{M}_{\mathrm{L}-\mathrm{LDG}} \leq 4 \\
\mathrm{M}_{\mathrm{w}}=0.664 \mathrm{M}_{\mathrm{L}-\mathrm{LDG}}+0.45 \text { for } \mathrm{M}_{\mathrm{L}-\mathrm{LDG}}<3.1,
\end{gathered}
$$

where (1) is from Braunmiller et al. (2005) confirmed by Cara et al. (2017) and (2) has been calibrated by Cara et al. (2015) using $\mathrm{M}_{\mathrm{w}}$ estimates from Godano et al. (2013). Refer to the dedicated paper about SiHex magnitudes and associated uncertainties for details (Cara et al. 2017).

SiHex $\mathrm{M}_{\mathrm{w}}$ estimates are directly used as input in the IPEs calibration process (see Sect. 3.2).

\section{SISFRANCE earthquakes seismological parameters estimates}

\subsection{French historical data}

For about 40 years, having been started in support of the development of the nuclear industry in France, efforts have been jointly made by BRGM (Bureau de Recherche Géologique et Minière), EDF (Electricité de France) and IRSN (Institut de Radioprotection et Sûreté Nucléaire) to collect, compile, and distribute information related to historical events. The SISFRANCE macroseismic database contains $\sim 100,000$ macroseismic observations (MSK intensity scale-Medvedev et al. (1967)) associated to $\sim 6000$ earthquakes (AD463-2007). These Intensity Data Points (IDPs) are representative of earthquake effects in terms of damages and population perception at various localities. The descriptions of these effects, used to assess intensity values are collected from historical archives for each event. Epicentral location is determined and provided, together with the epicentral intensity value when possible (see Lambert et al. (2015) for epicentral location and intensity assessment explanations). IDPs, epicentral intensity and location provided by SISFRANCE (2014 version) are used as a reference in the SIGMA project for IPEs calibration and the French historical events seismological parameters determination processes. IDPs are associated to quality factors that reflect confidence related to numerical value (quality A: certain intensity, quality B: fairly certain intensity, quality C: uncertain intensity). Epicentral intensity estimates are also associated to quality factors (quality A: certain epicentral intensity; quality B: fairly certain epicentral intensity; quality C: uncertain epicentral intensity, quality $\mathrm{E}$ : arbitrary epicentral intensity; quality $\mathrm{K}$ : fairly certain epicentral intensity, resulting from a calculation based on intensity attenuation). These quality index are used in the inversion processes weighting scheme (Baumont et al. submitted; Traversa et al. 2017). 
The largest earthquakes in metropolitan France are mainly located offshore or close to the borders where tectonic activity is mainly concentrated. This can imply some bias in the associated macroseismic field configuration. In addition, going back in time, smallest effects are often not handed down to nowadays, which implies that older events often suffer from the lack of a detailed description of their effects. As a consequence, according to the occurrence date of earthquakes and/or their location with respect to France borders, various macroseismic fields configuration can be observed in the SISFRANCE database as follows: (i) recent and largest events, located inside or close to the borders, exhibit large and well distributed macroseismic field, (ii) off-shore or cross border events, characterized by a lack of information at short distances but with reliable data at greater distances, and (iii) old events associated with a poorly constrained macroseismic field, where either only the epicentral intensity is quantitatively known or no intensity value is available, expect for few felt testimonies. These particularities have been kept in mind and considered at each step of the historical events seismological parameters determination process, both when developing IPEs (Baumont et al. submitted) and when building the inversion scheme of the SISFRANCE macroseismic data (Traversa et al. 2017).

\subsection{Intensity prediction equations (IPEs)}

Baumont et al. (submitted) companion paper focuses on IPEs calibration. A set of 30 calibration events inducing effects over the French metropolitan territory, with $\mathrm{M}_{\mathrm{w}}$ in the range 3.6-5.8, has been built. In order to supplement the dataset with larger magnitude events, and to extend the validity domain of developed IPEs, 11 Italian earthquakes, $\mathrm{M}_{\mathrm{w}} \geq 6.0$, were included as well (see Baumont et al. submitted for location and seismological parameters of these events). Earthquake parameters were issued from the SiHex catalogue (Cara et al. 2015) and early-instrumental study (Benjumea et al. 2015) for French or close to border events, while CPTI11 catalogue (Rovida et al. 2011) was used as reference for the Italian earthquakes parameters. Macroseismic data from the DBMI11 database (Locati et al. 2011) are used for Italian calibration events. Two functional forms, inspired from Kövesligethy (1907) and Sponheuer (1960) and that contain regional attenuation terms, are used:

$$
\begin{gathered}
\mathrm{I}=\mathrm{C}_{1}+\mathrm{C}_{2} \cdot \mathrm{M}_{\mathrm{w}}+\beta_{\mathrm{REGION}} \cdot \log _{10}(\mathrm{R}) \\
\mathrm{I}=\mathrm{C}_{1}+\mathrm{C}_{2} \cdot \mathrm{M}_{\mathrm{w}}+\beta \cdot \log _{10}(\mathrm{R})+\gamma_{\mathrm{REGION}} \cdot \mathrm{R}
\end{gathered}
$$

$\mathrm{M}_{\mathrm{w}}$ is the moment magnitude, $\mathrm{R}$ is the hypocentral distance of the isoseismals and $\mathrm{I}$ is the intensity level. The unknowns are $C_{1}$ and $C_{2}$ as part of the source term, $\beta$ as part of the geometrical spreading term and $\gamma$ as part of the intrinsic attenuation term. Such formulation has already been used to develop intensity attenuation models and to compute magnitudes and depths of past earthquakes around the world (Ambraseys 1985; Levret et al. 1994; Cecic et al. 1996; Musson 1996; Bakun and Wentworth 1997; Hinzen and Oemish 2001; Bakun 2006; Bakun and Scotti 2006; Beauval et al. 2010; Gasperini et al. 2010; Musson and Cecic 2012; Gomez-Capera et al. 2015).

In this study, in order to sample the epistemic uncertainty, a large set of IPEs has been developed (Baumont et al. submitted), based on:

- A set of 6 different metrics (i.e. various statistical measures) used to model intensity decay with distance $\left(\mathrm{R}_{\mathrm{AVG}}, \mathrm{R}_{\mathrm{OBS}}, \mathrm{R}_{\mathrm{P} 50}, \mathrm{R}_{\mathrm{P} 84}, \mathrm{R}_{\mathrm{F} 50}, \mathrm{R}_{\mathrm{F} 84}\right)$, that follows an intensity binning strategy (in addition to the brief description hereafter, refer to Baumont et al. 
(submitted) and Traversa et al. (2017) companion papers for detailed presentation). Differences come from the way chosen to calculate isoseismal radii by intensity levels (weighted barycenter of IDPs within a given class of intensity, for $\mathrm{R}_{\mathrm{AVG}}$, or the weighted barycenter, 50th percentile or 84 th percentile using an intensity bin width equal to zero, respectively for $\mathrm{R}_{\mathrm{OBS}}, \mathrm{R}_{\mathrm{P} 50}$ and $\left.\mathrm{R}_{\mathrm{P} 84}\right)$. $\mathrm{R}_{\mathrm{F}}$ metrics, also called felt radii, are only calculated on the smallest intensity for which the IDPs dataset is sufficiently large to allow unbiased estimates. These latter metrics are of primary interest when considering events characterized by information at large distances (typically off-shore or cross border events) as they deal with far field IDPs;

- 6 different sub-datasets with respect to intensity classes (number of intensity classesNc-for which isoseismals can be calculated) and distance (Dc) completeness. Datasets characterized by $\mathrm{Dc} \geq 30$ and $50 \mathrm{~km}$, together with $\mathrm{Nc} \geq 3,5$ and 7 are considered;

- a constraints scheme applied on the epicentral intensity (Io);

- the value above which IDPs (MCS intensity scale) coming from the DBMI database (Locati et al. 2011) are used in the calibration process [intensities $\leq$ VI or intensities $\leq$ VII following Traversa et al. (2014)].

Between and within events residuals analysis of these models have been performed to identify the more robust ones. Selected IPEs are calibrated with the 6 sub-datasets, the 6 developed metrics and 4 families of models that combine geographical zoning according to crust attenuation properties and constraints on Io (only mathematical formula with both geometrical spreading and intrinsic attenuation are considered, and only IDPs $\leq$ VII from the DBMI database are used). 144 IPEs have been selected (6 sub-datasets $* 6$ metrics $* 4$ families of models). This set of reference IPEs has then been used in the SISFRANCE macroseismic data inversion developed by Traversa et al. (2017) to compute historical earthquakes seismological parameters $\left(\mathrm{M}_{\mathrm{w}}\right.$ and depth), together with associated uncertainties.

\subsection{SISFRANCE macroseismic data inversion}

\subsubsection{Inversion scheme}

Traversa et al. (2017) companion paper details a dedicated strategy to compute seismological parameters of past events in France and neighbouring regions. $\mathbf{M}_{\mathrm{w}}$ and depth are estimated using the reference IPEs mentioned above in a Weighted Least Square (WLSQ) inversion process (Tarantola 2005), and combined in an exploration tree framework to take into account epistemic uncertainty related to the choice of model (see Traversa et al. (2017) for detailed description of the inversion method and of uncertainties computations). The exploration tree framework is presented in Fig. 1. In the inversion process, the macroseismic field configuration, together with the epicentral location with respect to the French borders, are considered to develop the most appropriate strategy to estimate $\mathrm{M}_{\mathrm{w}}$ and depth (Fig. 1).

Well documented earthquakes, which exhibit decay of intensity with distance, are processed differently depending on their location with respect to the French border (Fig. 1). $M_{w}$ and depths for events located within France plus a buffer of $15 \mathrm{~km}$, accounting for location uncertainties, are jointly computed using all reference IPEs (through "complete ET"). For events located outside this zone, the calculation is only performed with the 48 reference IPEs calibrated with felt radii $\left(\mathrm{R}_{\mathrm{F} 50}\right.$ and $\mathrm{R}_{\mathrm{F} 84}$; simplified ET), to take into account the lack of IDPs at short distances. Final $\mathrm{M}_{\mathrm{w}}$ and depth values are 


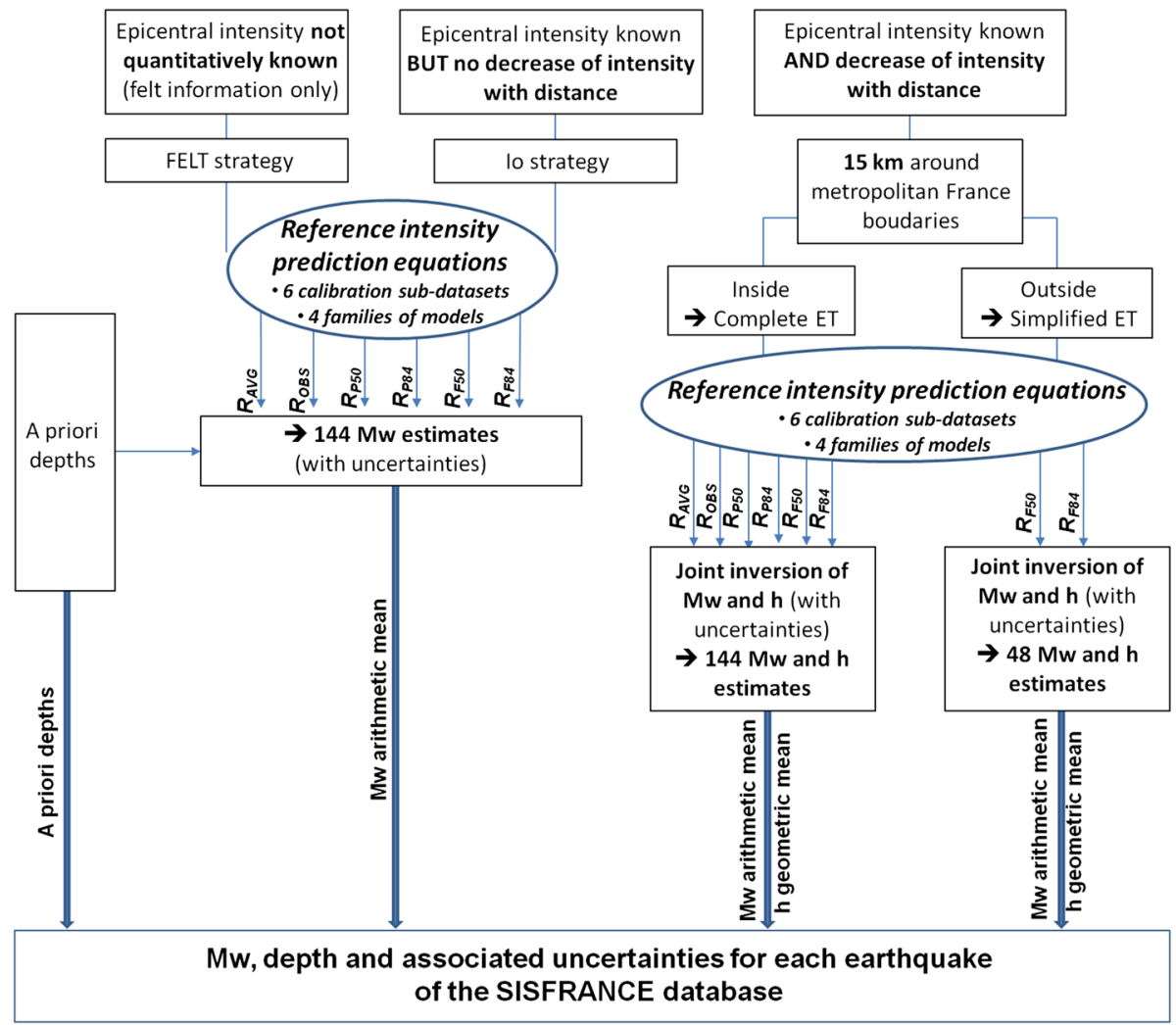

Fig. 1 Exploration tree framework for estimating $\mathrm{M}_{\mathrm{w}}$, depths and associated uncertainties of SISFRANCE past events

obtained as the arithmetic and the geometric means of individual $\mathrm{M}_{\mathrm{w}}$ and depth values, respectively. See Fig. 2 for the SISFRANCE epicenters locations according to the retained $15 \mathrm{~km}$ buffer around French boundaries.

\subsubsection{A priori depth characterization}

When either only the epicentral intensity is quantified or when no IDP is available (and consequently no decrease of intensity with distance is available), joint inversion of $M_{w}$ and depth cannot be performed. The only way to estimate moment magnitude is to fix a priori the earthquakes depth (Fig. 1). French territory and surrounding areas have been divided in 8 zones according to regional geological and seismological features as follow (Fig. 3):

- French Alps, Pyrenees and Armorican Massif areas have been kept as defined in Cara et al. (2015). They correspond to areas covered by regional catalogues and where observatory earthquake locations have been chosen as the preferred solution in the SiHex catalogue;

- European Cenozoic Rift System (ECRIS) zone delimits boundaries of the extensive structures (upper and lower Rhine grabens, together with the Bresse and Limagne grabens). Extension of this zone is deduced from Dezes et al. (2004); 


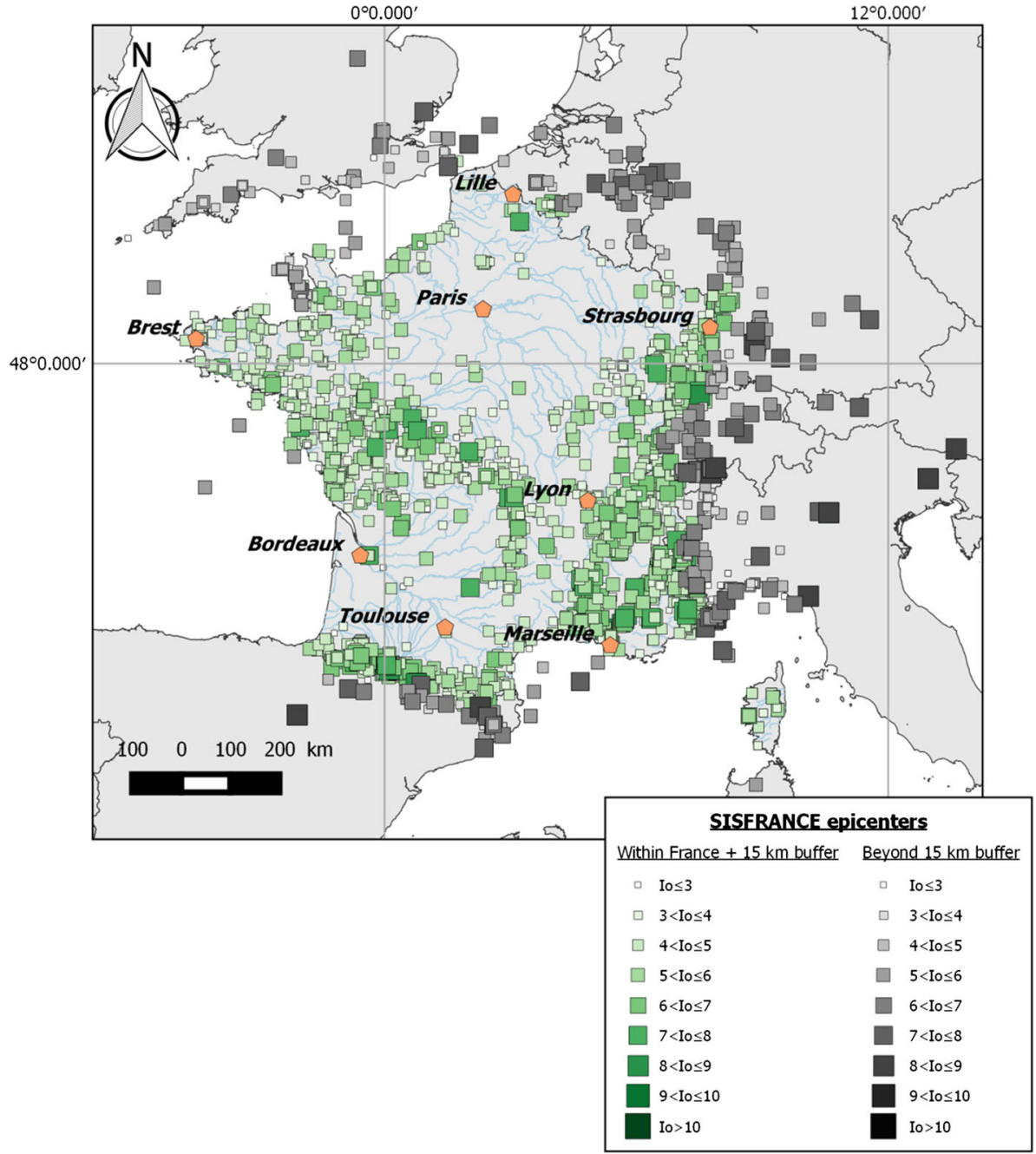

Fig. 2 SISFRANCE epicenters location (www.sisfrance.net). Green squares represent the epicenters of events located inside the $15 \mathrm{~km}$ buffer around French boundaries and for which $\mathrm{M}_{\mathrm{w}}$ and depth are computed through the complete exploration tree approach (use of all selected IPEs). Grey events are outside the buffer and benefit from the reduced exploration tree (IPEs calibrated with felt radii). Square sizes are defined according to epicentral intensity values

- Provence zone, composed for the Provence Panel of a mesozoic shelf basin and characterized by shallow seismicity (Baroux et al. 2001; Cushing et al. 2008);

- Tricastin zone, characterized by very shallow depth seismicity occurring through swarms (Thouvenot et al. 2009);

- Hainaut zone, also characterized by swarm seismic activity with shallow hypocenters (Camelbeeck 1985);

- Atlantic zone, that corresponds to the oceanic front (including southernmost part of United Kingdom and Chanel domain). 


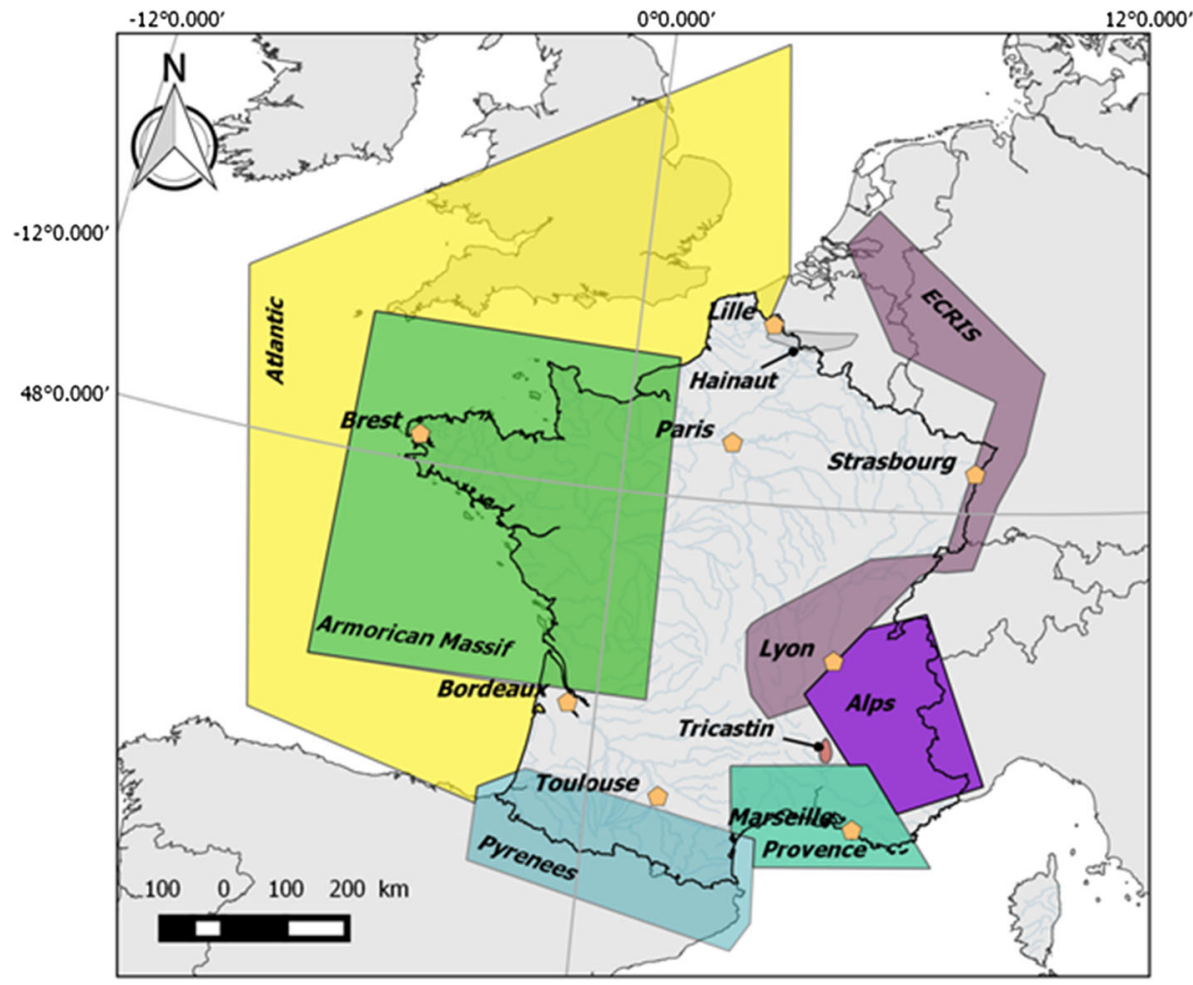

Fig. 3 Geological and seismological zonation for a priori seismogenic depth characterization. Armorican Massif, Alps and Pyrenees zones are from Cara et al. (2015). ECRIS zone is deduced from (Dezes et al. 2004)

The strategy adopted to estimate an a priori depth in each of these regions consists in performing a statistical analysis of regional depths computed through the WLSQ inversion for events falling in "complete" and "simplified" ET strategies. A priori depth by region is set to the median value of the depth distribution and associated minimum and maximum bounds correspond respectively to 16th and 84th percentile of the distribution. In practice, a detailed analysis of results coming from complete and simplified ET strategies has been performed to identify events that exhibit potentially biased $M_{w}$ and depth estimates and which may impact regional depths distribution. The goal is to avoid that $\mathbf{M}_{w}$ estimates of events processed with felt or Io strategies are biased. Analysis of complete and simplified ET results is given in Sect. 3.3.3.

Depth distributions by region are presented in Fig. 4a to $4 \mathrm{~h}$. Median values are retained as a priori depths, and correspond to values of 7, 14, 12, 9, 6, 3 and $15 \mathrm{~km}$, respectively for Alps, Armorican Massif, ECRIS, Pyrenees, Provence, Tricastin and Atlantic zones. Concerning the Hainaut zone, arbitrarily a priori depth has been set to $5 \mathrm{~km}$ as only 9 inverted depths are available, according to seismological and geological knowledge of this area (Camelbeeck 1985). For events located outside the 8 identified regions (called "Zone less" in Fig. 4; Table 1), the median value is equal to $11 \mathrm{~km}$. A summary of the regional median depths, together with the associated uncertainties (16th and 84th percentile of the distribution), are given in Table 1. Comparison between results obtained here with inverted 

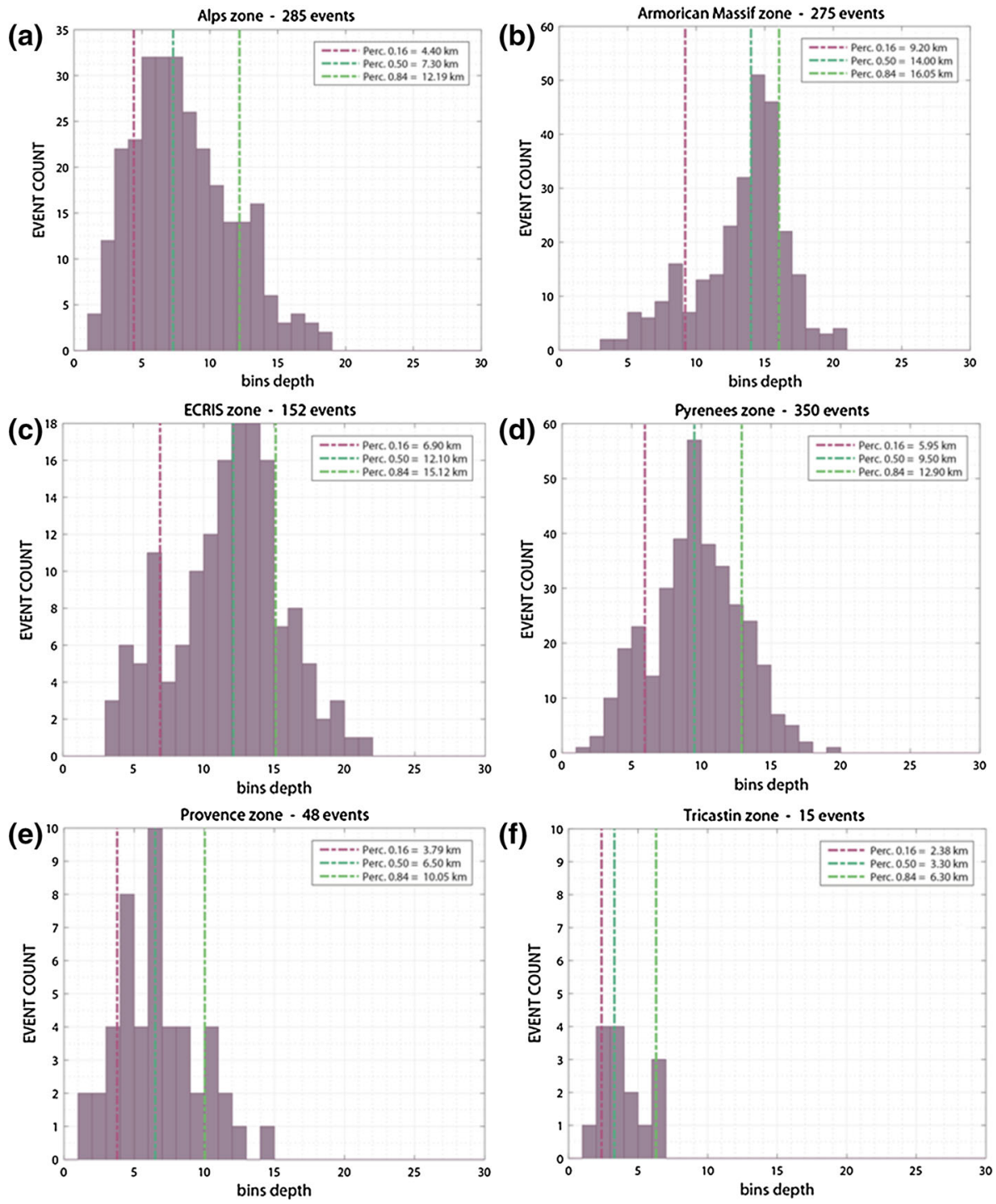

Fig. 4 Regional distribution of earthquake depths obtained with complete and simplified ET approaches. a Alps; b Armorican Massif; c ECRIS (European Cenozoic Rift System); d Pyrenees; e Provence; f Tricastin; g Hainaut; h Atlantic; i Zoneless. Purple, dark green and light green correspond to respectively 16th, 50th and 84th percentiles of the distributions. A priori depths are defined as the median values of each distribution

historical events depths and the use of SiHex instrumental depths has been performed in regions characterized by large amount of depth estimates. A priori depth estimates using the 2 approaches are consistent. 

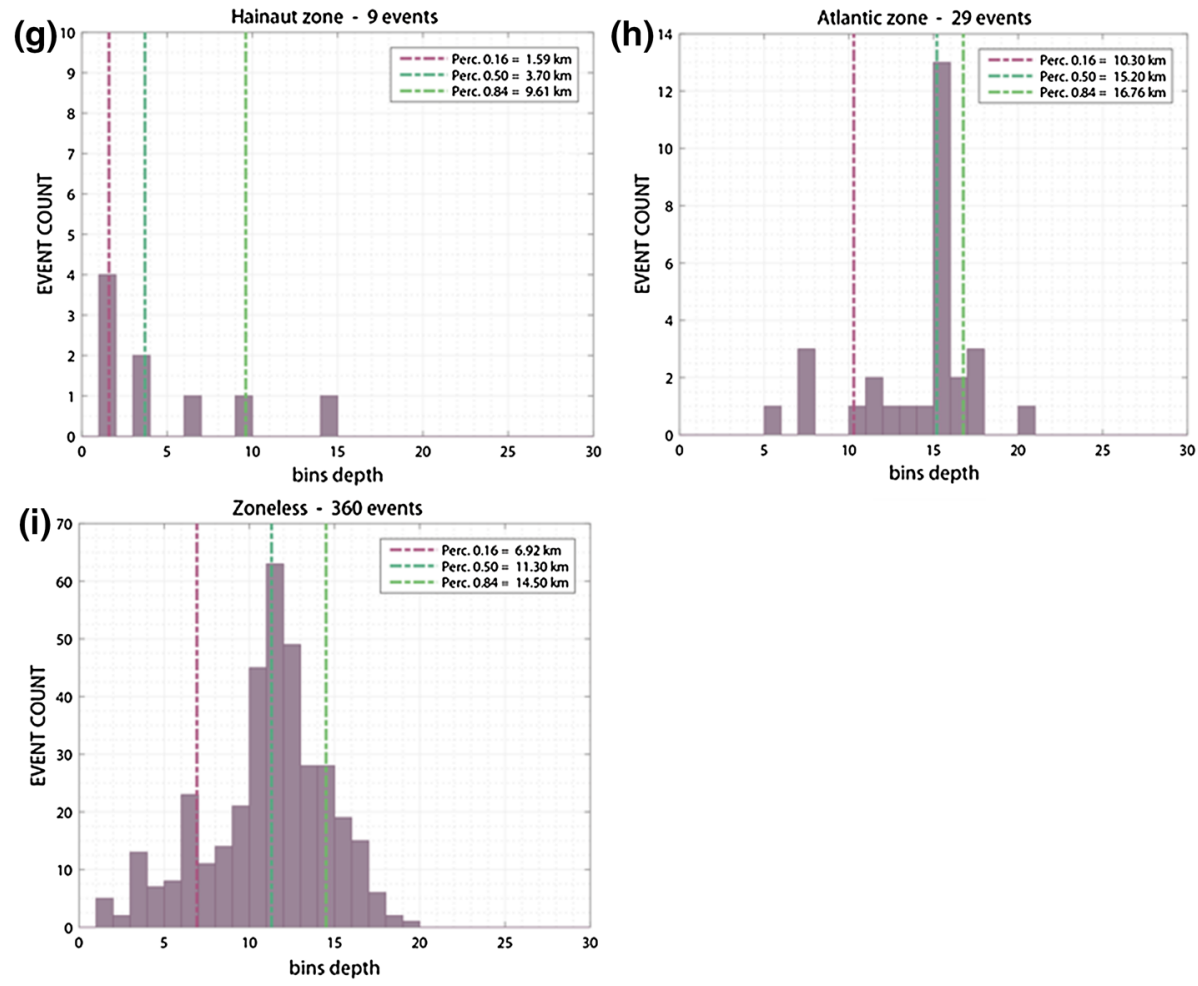

Fig. 4 continued

Table 1 Summary of regional a priori depths (median of computed past events depths distribution) and associated bounds (16th and 84th percentile of distribution associated respectively to minimum and maximum depths)

\begin{tabular}{lccc}
\hline Zone & A priori depth $(\mathrm{km})$ & Min depth $(\mathrm{km})$ & Max depth $(\mathrm{km})$ \\
\hline Alps & 7 & 4 & 12 \\
Pyrenees & 9 & 6 & 13 \\
Armorican Massif & 14 & 9 & 16 \\
ECRIS & 12 & 7 & 15 \\
Provence & 6 & 4 & 10 \\
Tricastin & 3 & 2 & 6 \\
Hainaut & $5^{\mathrm{a}}$ & $2^{\mathrm{a}}$ & $8^{\mathrm{a}}$ \\
Atlantique & 15 & 10 & 17 \\
Zoneless & 11 & 7 & 14 \\
\hline
\end{tabular}

${ }^{a}$ Arbitrarily fixed values 


\subsubsection{Application to SISFRANCE earthquakes}

The inversion scheme presented above (Traversa et al. 2017) (Fig. 1) aims at accounting for particularities in the macroseismic field inherent in the occurrence date of earthquakes, and to event locations relative to the French border. However, the different strategies adopted in the inversion scheme cannot take into account specific macroseismic field details related to the behavior of particular events and cannot be applied blindly without risk of introducing a bias to the estimates. In practice, we have opted to perform the application following the flowchart presented in Fig. 5. The step identified as "detailed analysis" of results consists of examining $\mathrm{M}_{\mathrm{w}}$ and depth estimates, obtained with complete and simplified ET strategies, in order to identify results which are possibly inconsistent with the French geological and seismological global context, that is $M_{w} \geq 5.8$, depth $\leq 2 \mathrm{~km}$ or $\geq 20 \mathrm{~km}$. If, for an earthquake, the analysis concludes that the joint inversion of $\mathrm{M}_{\mathrm{w}}$ and depth gives results with no clear inconsistencies, these estimates are kept. If not, Io or felt strategies are used for this event according to its IDPs configuration. This bias tracking is also of primary interest for regional a priori depth characterizations as unconstrained results coming from the complete and simplified ET may have an impact on depth distribution (see Sect. 3.3.1; Fig. 5).

Calibration events are special cases, as they benefit from instrumental estimates of $\mathrm{M}_{\mathrm{w}}$ and depth. We decided, for these events to constrain the inversion such that the seismological parameters coul only vary within the uncertainty range associated to the instrumental estimates, used in IPEs calibration process. To do so, minimum and maximum values defined in Baumont et al. (Submitted) have been used to limit the exploration domain.

\subsubsection{Quality control on results}

As described above (Sect. 3.3.3; Fig. 5), criteria for specific event by event analysis are set arbitrarily to $\mathrm{M}_{\mathrm{w}} \geq 5.8$ and depth $\leq 2 \mathrm{~km}$ or $\geq 20 \mathrm{~km}$. The earthquakes respecting these criteria are listed in Table 2. Events falling in the category with both depth $\geq 20 \mathrm{~km}$ and

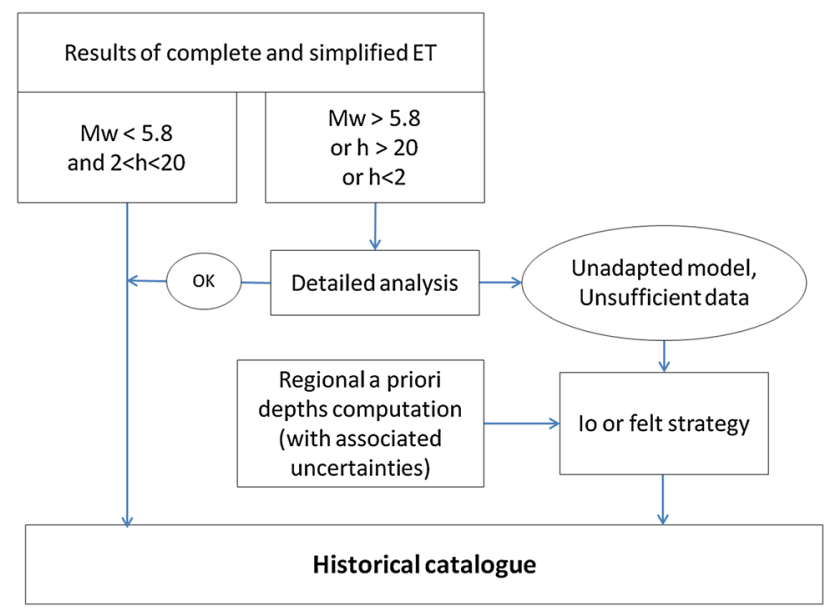

Fig. 5 Flowchart of inversion process developed by Traversa et al. (2017) (see Sect. 3.3.1) that includes quality control of first order results coming from complete and simplified ET 


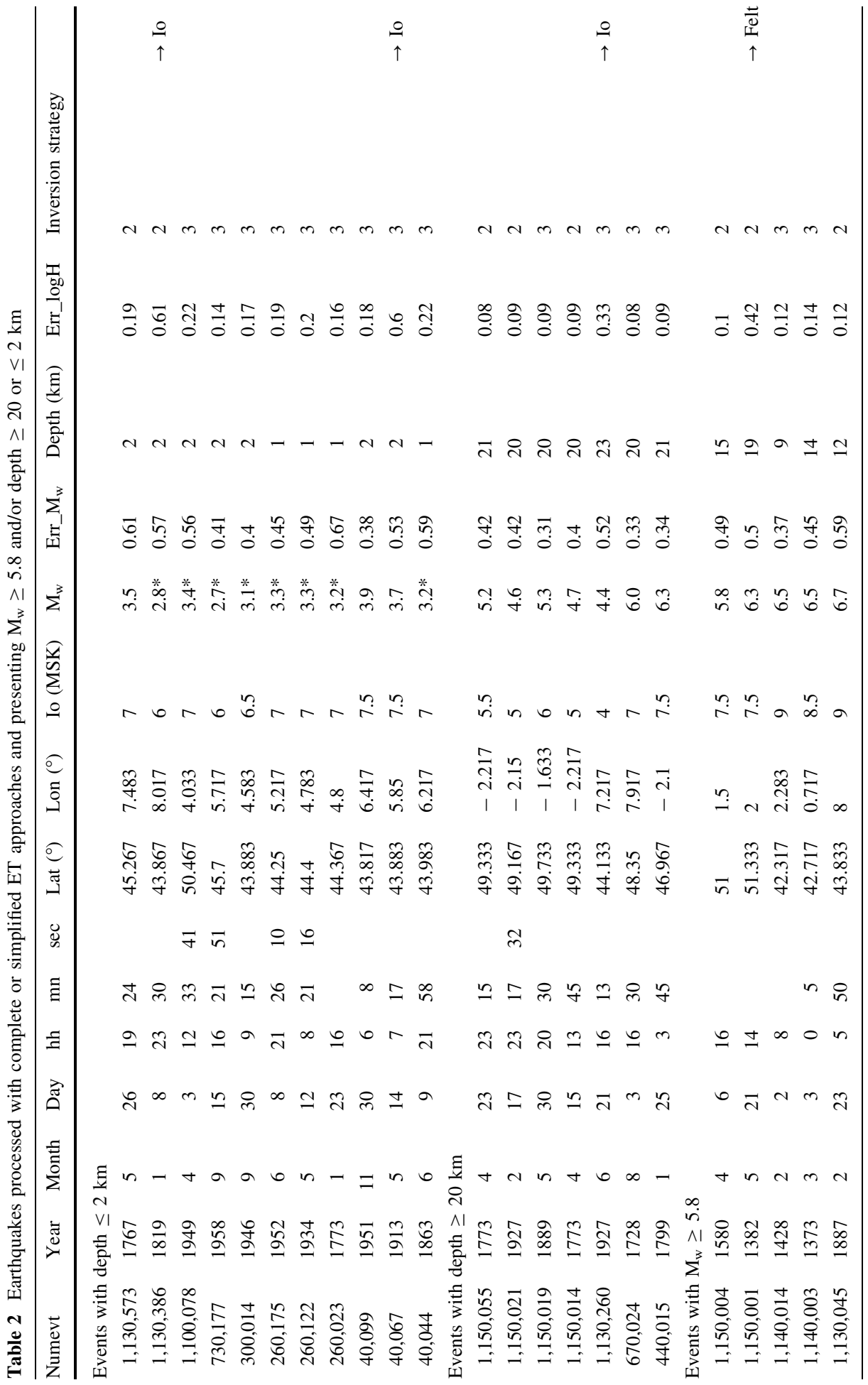




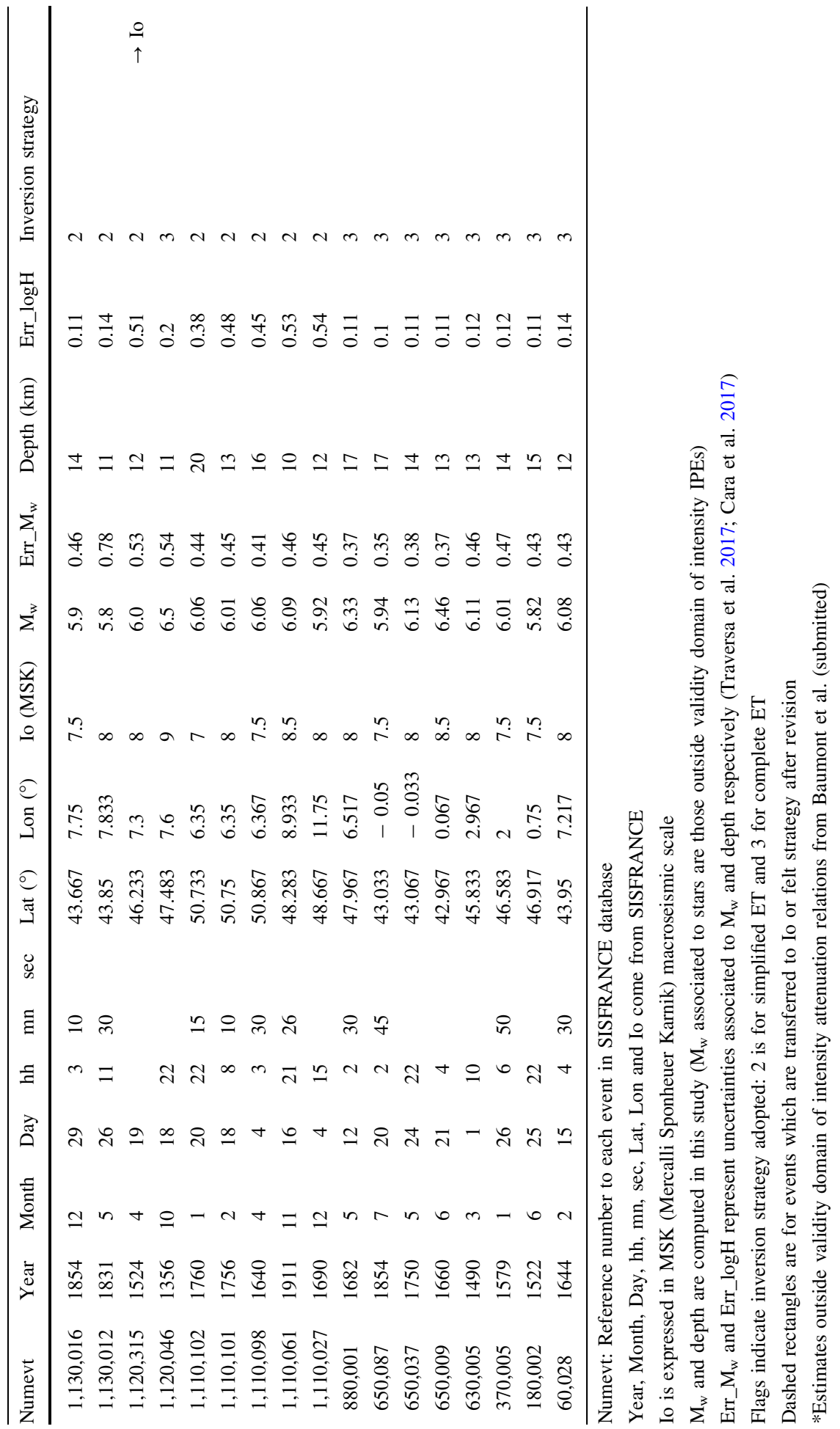


with $\mathrm{M}_{\mathrm{w}} \geq 5.8$ are only listed once in the table in section "events with depth $\geq 20 \mathrm{~km}$ ". After a detailed inspection of the macroseismic fields, in terms of data available (IDPs $v s$ felt testimonies) and the constraint on intensity decay with distance, only 5 events (dashed rectangles in Table 2) have been transferred to either Io (4 earthquakes) or felt strategies (1earthquake).

The example of the 19 April 1524, Valais earthquake (Io = VIII MSK; SISFRANCE reference number 1120315) is provided in Fig. 6. In this case, the macroseismic field is poorly constrained, with only 4 IDPs at short distances and 1 felt testimony (in Basel). Decay of intensity with distance is dominated by the conversion of the felt testimony into IDPs following the method described in Traversa et al. (2017). $\mathbf{M}_{\mathrm{w}}$ and depth estimates using the simplified ET branch are equal to $M_{w} 6.0$ and $12 \mathrm{~km}$, respectively. As the most reliable information available for this earthquake is located at short distances, we finally opted for the use of the Io strategy to estimate the seismological parameters of this

(a)
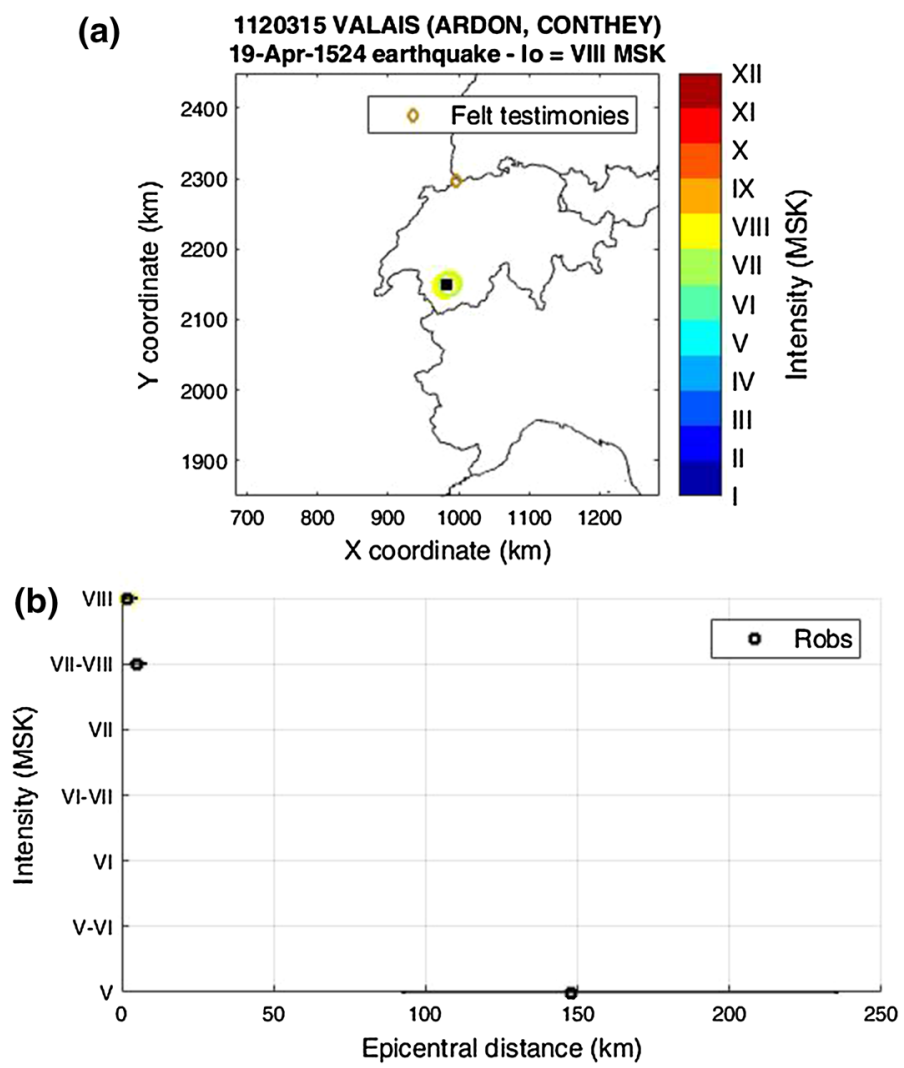

Fig. 6 Macroseismic field associated to the 19 April 1524 Valais earthquake (Io = VIII MSK; SISFRANCE reference number 1120315). The map a shows that only 2 IDPs are available (circles with colour and size related to the intensity value) and one reported felt testimony (pale gold diamond north of the epicentre, close the meeting point of France, Switzerland and Germany). The black square is for epicentre location. Decay of intensity is given in the plot (b). Dark circles are for isoseismals radii obtained using the $\mathrm{R}_{\mathrm{OBS}}$ intensity binning strategy. The intensity V MSK large distance IDP comes from the felt testimony converted into a quantified intensity value based on the date of occurrence (Baumont et al. submitted; Traversa et al. 2017) 
earthquake. Notice that, in this case, the $\mathrm{M}_{\mathrm{w}}$ inferred through the Io strategy $\left(\mathrm{M}_{\mathrm{w}}=5.9\right.$ and setting the depth to $11 \mathrm{~km}$, for the zoneless region) is consistent with the one obtained through the simplified ET.

The case of the 21 May 1382, North Sea earthquake (Io = VII-VIII MSK; SISFRANCE reference number 1150001) is different. This event is located off-shore and no IDPs are available close to the epicenter location. The epicenter is provided by SISFRANCE based on expert judgment, with associated quality index D (strongly assumed location-uncertainty in the range of a few $\mathrm{km}$ to $50 \mathrm{~km}$ ). If some IDPs reported from about $60 \mathrm{~km}$ are included, the macroseismic field of this event is dominated by felt testimonies (Fig. 7b). Lack of information at short distance, uncertainty of the epicentral location and a significant number of felt testimonies led us to switch to the felt strategy to estimate $\mathrm{M}_{\mathrm{w}}$ of this event. In addition, intensity decay with distance presented in Fig. $7 \mathrm{~b}$ does not appear reliable based on the epicentral intensity estimated by SISFRANCE (Io = VII-VIII MSK). As a result, seismological parameters estimates change from
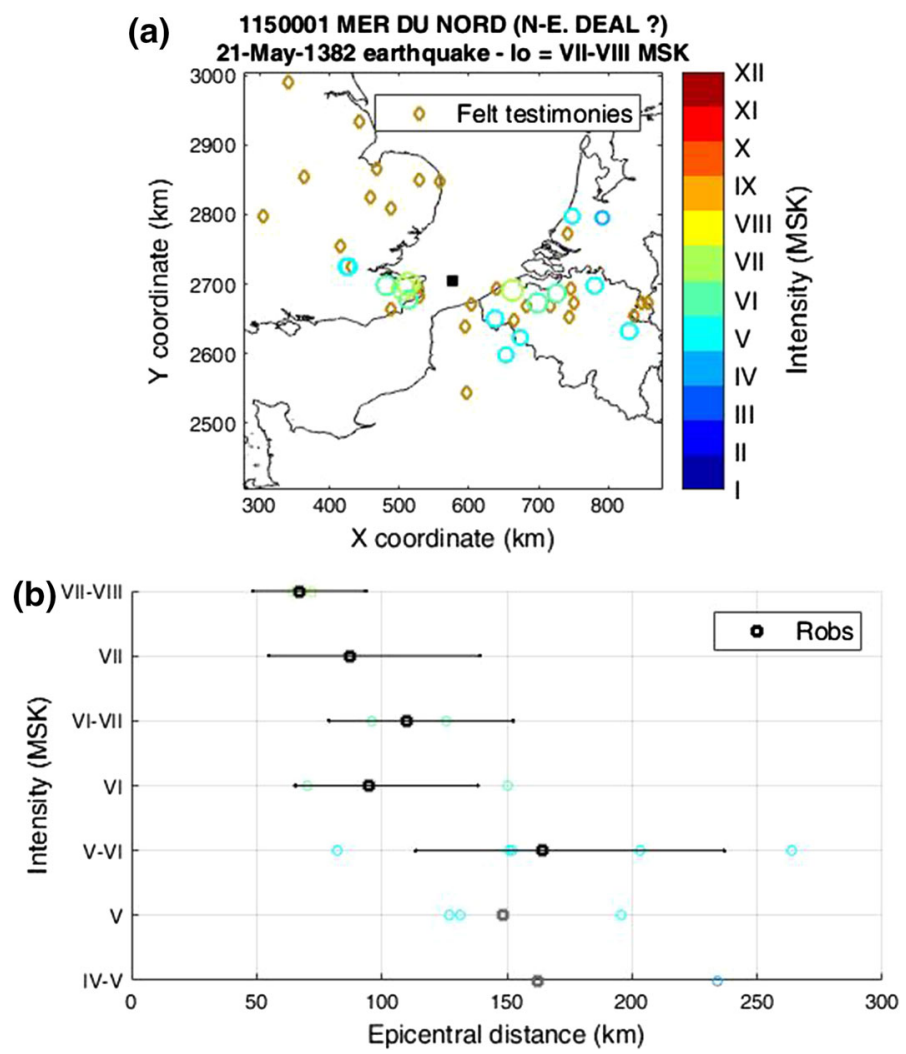

Fig. 7 Macroseismic field associated to the 21 May 1382 North Sea earthquake (Io = VII-VIII MSK; SISFRANCE reference number 1150001). The map a shows that only a few IDPs (circles with colour and size related to intensity value) are available compared to felt testimonies (pale gold diamonds). The black square is the epicentre location. The intensity decay is given in (b). Dark circles are for isoseismal radii obtained using the $\mathrm{R}_{\mathrm{OBS}}$ intensity binning strategy. Grey circles are for $\mathrm{R}_{\mathrm{OBS}}$ falling outside the calculated intensity completeness. Coloured circles are for IDPs 
$\mathrm{M}_{\mathrm{w}}=6.3$ to $\mathrm{M}_{\mathrm{w}}=6.0$ and depth from $19 \mathrm{~km}$ to $15 \mathrm{~km}$ (i.e. a priori depth of the Atlantic zone).

Figure 8 illustrates an example where macroseismic field analysis, together with intercomparison of events located close to each other, help us to quantify the reliability of $\mathrm{M}_{\mathrm{w}}$ and depth estimates for a poorly constrained event. This shows three events, located in the Jersey area. Two in 1773 (15 and 23 April, with Io = V and V-VI respectively; SISFRANCE reference numbers $=1150014$ and 1150055) and one in 1927 (17 February, with Io $=$ V; SISFRANCE reference number $=1150021$ ). For these 3 earthquakes, depth estimates are $\sim 20 \mathrm{~km}$ when considering simplified ET results. Looking at the well constrained decay of intensity with distance for the 1927 event, characterized by a large set of IDPs and well organised associated isoseismal radii, seismological parameters estimates for this event appear to be reliable. Considering the 15 April 1773 event, decay of intensity with distance is less constrained than for the 1927 event, nonetheless it is controlled by 3 clearly defined isoseismal radii (Fig. 8). The associated depth estimate of about $20 \mathrm{~km}$ can also be considered reliable. Decay of intensity with distance for the 23 April 1773 event is controlled by only 2 points (IDPs with intensity of IV-V are not considered as they are below the calculated intensity of completeness). Taking into account its geographical proximity to the 1927 and the 15 April 1773 events, and the similarity of the depth estimated for each of the 3 events, we have kept the depth for the 23 April 1773 event despite the low level of constraint on the decay of intensity with distance. Notice that the 30 July 1926 Jersey event, which is the largest earthquake known in this area, exhibits an estimated $16 \mathrm{~km}$ depth, based on simplified ET strategy. Taking into account uncertainties associated with earthquake depth estimates, this estimate appears consistent with the $20 \mathrm{~km}$ depths obtained for the 1773 and 1927 earthquakes.

At the end, $21 \%$ of the SISFRANCE earthquakes have been processed with a complete ET approach, $6 \%$ benefit from the simplified branch and $27 \%$ have an Io strategy based $\mathrm{M}_{\mathrm{w}}$ estimates. For the remaining $46 \%$, the $\mathrm{M}_{\mathrm{w}}$ comes from a felt strategy.

Taking advantage from the 40-years-long overlap of the SiHex catalogue with the SISFRANCE database, a comparison between $\mathrm{M}_{\mathrm{w}}$ and depths estimates coming from SISFRANCE data inversion and from SiHex computation has been realized. Common events between the two datasets have been identified by looking at the date and time of the events together with their location. At the end 588 events are compared. Results are presented in Fig. 9, with the $\mathrm{M}_{\mathrm{w}}$ comparison on the left panel and depths one on the right panel.

We can observe that no particular bias appears between the two datasets concerning magnitudes, even if there is dispersion of about half a magnitude degree on both sides of the identity line below magnitudes of around 3.5. Still for magnitudes lower than 3.5 we note that SiHex magnitudes distribution exhibit alignments at each step of 0.1 degree of magnitudes. This is due to the fact that below magnitudes $\mathrm{M}_{\mathrm{L}}-\mathrm{LDG}=4.0$ (i.e. $\left.\mathrm{M}_{\mathrm{w}}=3.4\right), \mathrm{M}_{\mathrm{w}}$ estimates provided by SiHex come from the use of magnitude conversion laws (Cara et al. 2017; Sect. 2). Above magnitude 3.5 the consistency between the different estimates is overall better and is even really satisfying above $\mathrm{M}_{\mathrm{w}}$ around 4.0. On the whole, we show that $\mathrm{M}_{\mathrm{w}}$ coming from SiHex and those coming from macroseismic data inversion are correlated, which consequently tends to lend weight to our retained approach (IPEs derived from France and application through an ET framework) and to $\mathrm{M}_{\mathrm{w}}$ estimates for past events.

Analysis of comparison between depths shows no evidences of any consistency between the estimates. This distribution can be explained by (i) the fixed a priori depths used in this study, that are brought out through dots alignments at 7, 9 and $14 \mathrm{~km}$ (see Fig. 9—right 

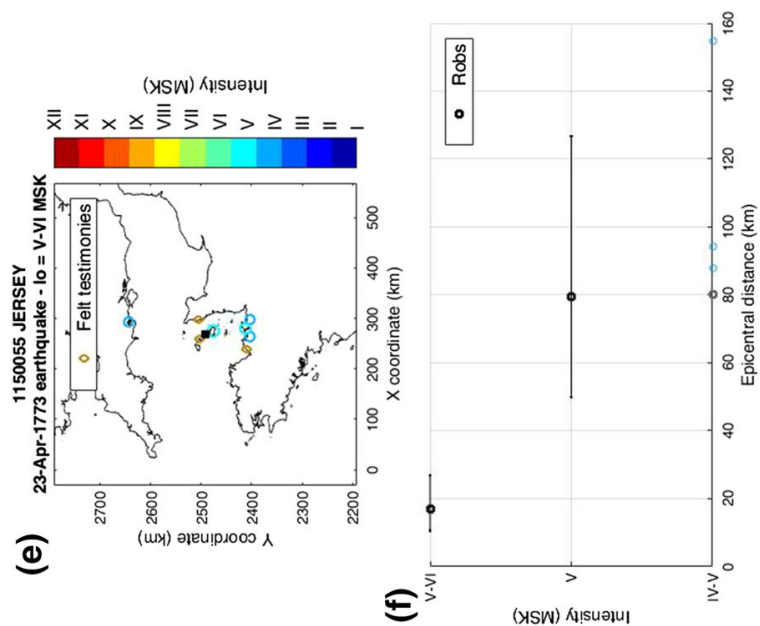

象

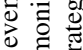

诺

可产

를

บ 粦

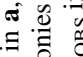

ช。

过

可

卷

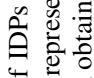

능

जै 0े

之过

롱 종

d) 응

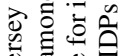

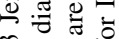

궁

을

远范揱

حิ

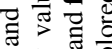

을

들

$\Xi . \Xi$

过ᄋ

on ond

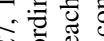

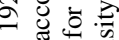

춸 월

के के

$\therefore$ 들

응 웡

․․․․․․

을

호

零 की

वे के ज्ञ

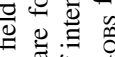

.

हี

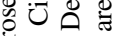

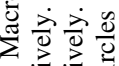

$\infty$ 䲶

ज० क्षे के

(ี) 

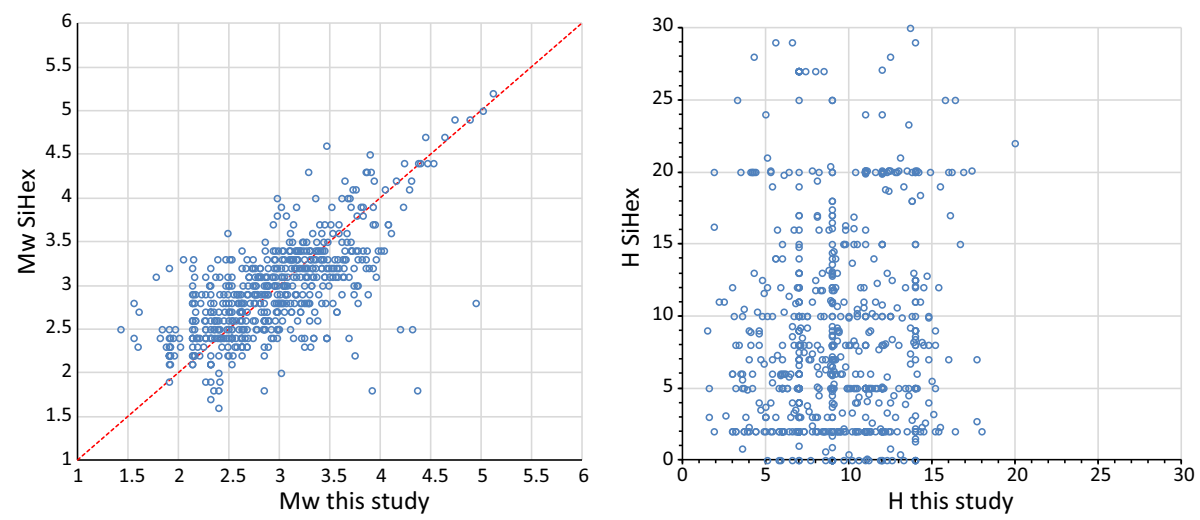

Fig. 9 Comparison between $\mathrm{M}_{\mathrm{w}}$ (left) and depths (right) coming from ET approach and estimates provided by the SiHex catalogue for events (blue circles) between 1965 and 2007 (overlapping period of the SiHex catalogue and the SISFRANCE macroseismic database). Red dashed line in left panel is for the identity

panel), as well as by (ii) the poorly constrained depths estimates in the SiHex backbone catalogue that concentrate at different depth levels, visible at 2, 5, 10 and $20 \mathrm{~km}$ depth on Fig. 9 (right panel).

\section{The French seismic CATalogue (FCAT-17)}

The FCAT-17 catalogue has been produced by merging the SiHex instrumental catalogue (Cara et al. 2015) and the SIGMA seismological parameters estimates for historical earthquakes (this article and Traversa et al. (2017) and Baumont et al. (Submitted) companion papers). The date at which the 2 catalogues are concatenated has been set to the year 1965. This is become of the following: (i) since that year the seismic network is installed homogenously within the French metropolitan territory (SiHex team personal communication) and (ii) since this date there has been no further development of the stations used for the coda magnitude computation in the SiHex catalogue.

The FCAT-17 catalogue is presented on a map Fig. 10, and is also provided as supplementary material to this article, in Excel format. The explanation for the format of the different fields present in the table is given in a dedicated sheet of the Excel file. Refer to Traversa et al. (2017) for a detailed explanation of the computation of moment magnitude, $M_{w}$, and depth uncertainties for historical events and to (Cara et al. 2017) for a presentation of the assessment of uncertainties in the moment magnitude, $\mathrm{M}_{\mathrm{w}}$, in the SiHex catalogue.

Only $\mathrm{M}_{\mathrm{w}}$, depths and associated uncertainties of historical earthquakes located within the French borders extended with a buffer of $40 \mathrm{~km}$ are provided in the FCAT-17 catalogue table (supplementary material). These data correspond to the coloured circles on the map in Fig. 10. The objective has been to take into account the potentially large uncertainties in the epicentral location when managing D quality index attributed in SISFRANCE. In addition, we consider that cross border events, located beyond the $40 \mathrm{~km}$ limit, benefit from a better characterization when considering local data, and that consequently, estimates associated seismological parameters coming from national catalogues also have to be considered. These events, represented as grey circles in Fig. 10, are plotted for information purpose only, and their $\mathrm{M}_{\mathrm{w}}$ and $\mathrm{h}$ estimates are not indicated in the FCAT- 


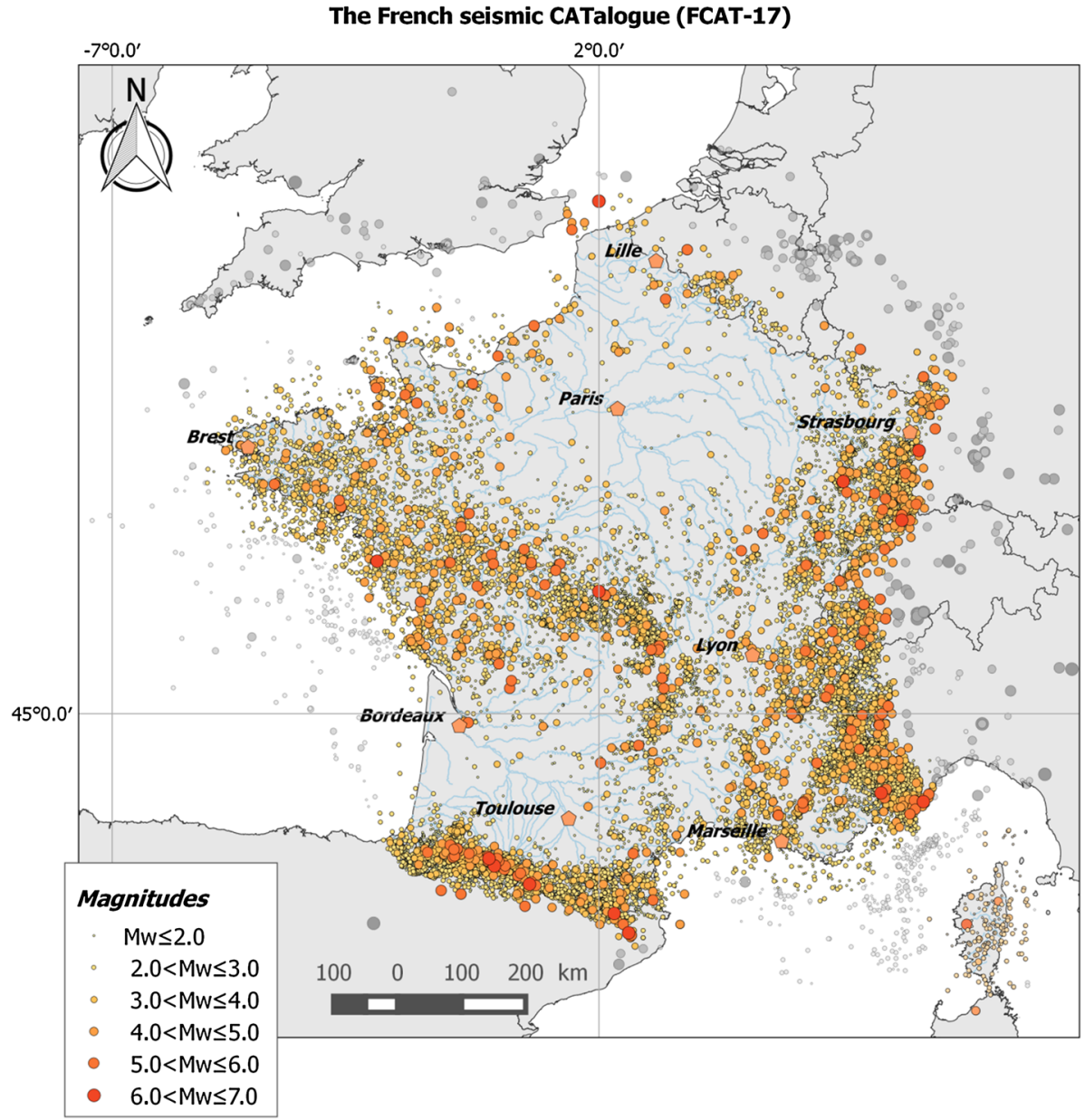

Fig. 10 The French seismic CATalogue (FCAT-17). Size and colour of circles are defined according to magnitude values. Grey circles are epicenters stored in SISFRANCE database (and is consequently not representative of regional seismicity as no data from cross-border seismological agencies are considered) located outside France plus a buffer of $40 \mathrm{~km}$ and not included in the provided FCAT-17 catalogue (supplementary material)

17 table. One can notice that the earthquake distribution outside France boundaries (grey dotes) represents epicenters stored in the SISFRANCE database. Data coming from cross border agencies are not included in Fig. 10 and the picture consequently does not traduce seismicity behavior outside France. SiHex data are only available within the France territory extended by a buffer of $20 \mathrm{~km}$ due to the fact that SiHex project is not authoritative on data located beyond, except within the French marine exclusive economic zone (ZEE) where data are provided (Cara et al. 2015). Same rules apply to instrumental earthquakes in the FCAT-17 catalogue.

As a result of the assumptions and decisions made during this work, end users have to keep in mind the following important points: 
- IDPs, epicentral location and intensity are considered as they are set in SISFRANCE database without any revision (see Traversa et al. (2017) for discussion on the use of SISFRANCE epicenters location). These values are used both when calibrating IPEs and estimating $\mathrm{M}_{\mathrm{w}}$, depths and associated uncertainties. The uncertainties affecting the IDPs and epicenter features, which are expressed in SISFRANCE database through quality indexes, are taken into account and used in weighting schemes for calculation. For a given event, it could be useful to go back to archives interpretation, in order to allow improving IDPs characterization and consequently earthquakes seismological parameters estimates;

- Regional attenuation domains are defined on the basis of the Mayor et al. (2017) intrinsic attenuation map at $1 \mathrm{~Hz}$, and used for both IPEs calibration (Baumont et al. submitted) and their application to past events. Regionalized attenuation and national intensity prediction equations are considered as different branches in the ET (Traversa et al. 2017). When the uncertainty on the earthquake location is high, attributing an event to an attenuation region might be erroneous. In addition, southeastern part of France, characterized by heterogeneity in term of attenuation properties (Mayor et al. 2017), could benefit, in next steps of this work, from an increased precision in defining IPE zones.

- IPEs developed by Baumont et al. (submitted) are valid on a range of $\mathrm{M}_{\mathrm{w}}$ covering 3.5 up to 7.0. Some events exhibit, coming out of the exploration tree, $\mathrm{M}_{\mathrm{w}}$ estimates out of these validity bounds. They have been kept in the final catalogue, as flagged values (with a star), for information purpose only as we do not guarantee reliability of these estimates.

- Depths estimates for historical events (before 1965) can be of two origins, inverted or a priori set by region. To underline this difference and associated level of reliability on depths values, they are split, in the FCAT-17 table (supplementary material), in two columns, one for inverted depths and the other for fixed ones.

- One can be aware that for poorly characterized past events moment magnitude and depth estimates are correlated;

- In spite of the fact that inversion scheme developed by Traversa et al. (2017) aims at dealing with the most common macroseismic field configurations observed in SISFRANCE and that quality control has been performed on suspicious results, no systematic verification and validation was carried out event by event. As a consequence, for some of the events automatically treated, the inversion scheme might be manually improved.

Considering the limits discussed above, a quality index is associated to each earthquake that belongs to the historical period (before 1965). "Good" index deals with event benefiting from Complete LT inversion procedure and "fair" with earthquakes processed through Simplified LT. Concerning felt strategy the associated index is "poor". Finally, Io based earthquakes are flagged "Educated Guess".

\section{Comparison with previously published catalogues}

The SHARE European Earthquake Catalogue (SHEEC) AD1000-1899 has been compiled within the framework of the EC project "SHARE" (Seismic Hazard Harmonization in Europe; 2009-2012) (Stucchi et al. 2012). The SHARE European Earthquake Catalogue (SHEEC) 1900-2006 has been compiled by GFZ Potsdam in the framework of an 

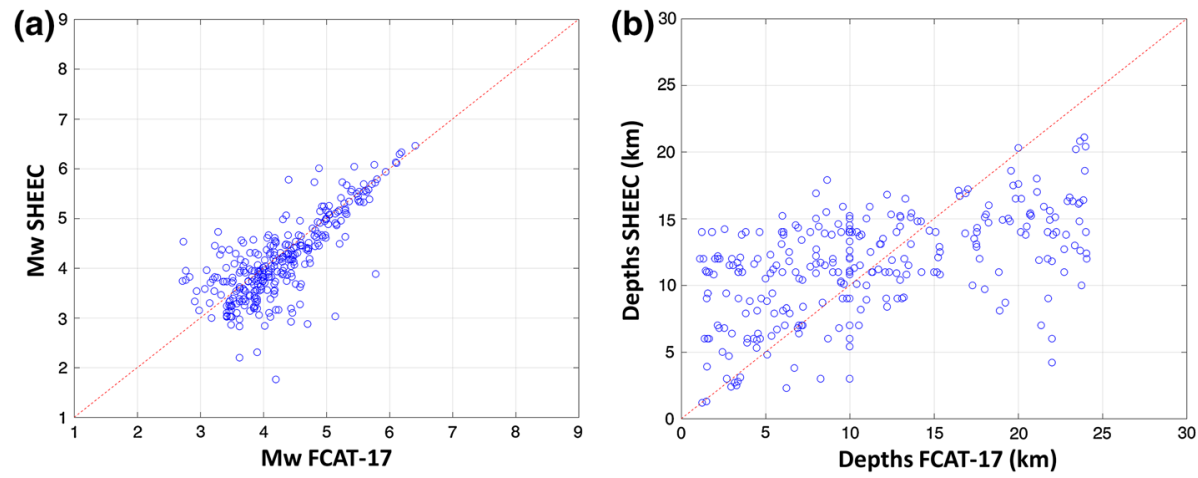

Fig. 11 Comparison, in terms of a Moment magnitude, $\mathbf{M}_{\mathrm{w}}$, and $\mathbf{b}$ depth, between the SHEEC catalogue and the parameters obtained during this work. Data represents earthquakes occurring in the period AD10002006 - blue circles. The red dotted lines represent equality

independent project and represents a temporal and spatial excerpt of "The EuropeanMediterranean Earthquake Catalogue" (EMEC) for the last millennium (Grünthal and Wahlström 2012) with a few modifications that are described in Grünthal et al. (2013).

The two SHEEC and EMEC catalogues have been concatenated in order to compare their seismological parameter estimates to those presented in the FCAT-17 catalogue. 353 common events can be identified, by comparing date and time of the events together with location. Figure 11 (left panel) shows the comparison between the $\mathrm{M}_{\mathrm{w}}$ magnitudes provided by the SHEEC catalogue and the $\mathrm{M}_{\mathrm{w}}$ computed in this work. No particular bias can be identified between the two catalogues estimates. There is a rather large scattered of results around the identity line at low magnitudes, but the agreement becomes more consistent at moderate-to-large magnitudes. Figure 11 (right panel) presents the comparison between the earthquake depths estimates. In this case, the dispersion of the data around the identity line is important but it can be seen that below around $15 \mathrm{~km}$ SHEEC depth estimates are higher than FCAT-17 depth estimates. For deeper events SHEEC depths are shallower than FCAT-17 ones.

\section{Conclusion}

In this study, we have implemented a parametric earthquake catalogue using moment magnitude, $\mathrm{M}_{\mathrm{w}}$, as the reference magnitude scale covering the metropolitan France for both instrumental and historical times (FCAT-17). It has been built by merging the instrumental seismic catalogue coming from the SiHex project (Cara et al. 2015) and the seismological parameters estimated for the SISFRANCE historical earthquakes within the framework of the SIGMA project. This latter includes an integrated study of historical seismicity aimed at (i) calibrating the IPEs adapted to the western European geological context (Baumont et al. submitted), (ii) developing an inversion scheme that takes into account the different macroseismic field configurations observed in SISFRANCE database, together with the epistemic uncertainty inherent in the choice of IPEs (Traversa et al. 2017) and (iii) applying this inversion procedure to the SISFRANCE macroseismic data (this paper). 
Both the SiHex and SIGMA seismological parameters estimates are based on identified and well documented procedures. Specific work has been performed on characterizing uncertainties associated with computed $\mathrm{M}_{\mathrm{w}}$ and depths (Cara et al. 2017; Traversa et al. 2017). In the case of major instrumental events $\left(M_{w} \geq 3.4\right)$ and historical events, no magnitude conversion has been used to estimate $\mathrm{M}_{\mathrm{w}}$. This contributes to withdraw uncertainties linked to the use of magnitudes conversion relationships (e.g. Braunmiller et al. 2005; Scordilis 2006; Grünthal et al. 2009). As a result, this catalogue can be directly used as an input for seismic hazard assessment studies and uncertainties propagation is reduced.

In the SIGMA works on the historical period, $27 \%$ of the SISFRANCE events benefit from a joint inversion of $\mathrm{M}_{\mathrm{w}}$ and depth. It concerns events that exhibit satisfying macroseismic field with reliable decay of intensity with distance. $73 \%$ of past earthquakes require a priori depth estimate to compute $\mathrm{M}_{\mathrm{w}}$, due to their poorly constrained macroseismic field. Specific attention has been paid in this study to the regional a priori depth computation. Depth inversion has been performed on the $27 \%$ "well constrained" events to determine the depth distribution within specific regions. The "preferred" depth has been defined as the median of the distribution but the associated lower and higher boundaries (respectively 16th and 84th percentiles of the distribution) have also been identified. Regions are defined following geological and seismological contexts. Nine regions have been identified as follows: Alps, Armorican Massif, Pyrenees, European Cenozoic RIft System (ECRIS), Provence, Atlantic, Hainaut, Tricastin and Zoneless (all other areas). Only a few events are located in the Hainaut zone, and the depth distribution is not good enough to calculate a constrained preferred regional depth without associated uncertainties. In this region, the preferred depth has been set arbitrarily by taking into account existing knowledge of the seismological behaviour of the region (Camelbeeck 1985). For the Tricastin and Atlantic zones; depth distribution is also poorly constrained but the respective preferred depths (from the median) and the associated upper and lower boundaries coming from the 16th and 84 th percentiles have been retained as they seem to reflect the regional seismological context.

Quality control checks have been undertaken to identify and remove any bias inherent to some event macroseismic field data. Considering that an inappropriate inversion strategy can produce unreliable results, each event that presents an unusual $\mathbf{M}_{\mathrm{w}}$ and depth estimates with respect to the geological and seismological context of the respected area is analyzes further in details. Where necessary, an inversion process was forced to switch to the most appropriate strategy depending on the event macroseismic field configuration (only 5 events were affected in this way).

To produce the FCAT-17 catalogue, the concatenation date between the instrumental and historical parts has been set to the year 1965. Since this date the French seismological network is considered to have been homogenously distributed throughout France. Also, stations used for the coda magnitude computation in the SIHex catalogue have not faced evolution. The FCAT-17 catalogue is presented on a map (Fig. 10) and is also available digitally in a table as an Excel file provided as supplementary material. Uncertainties associated to $\mathrm{M}_{\mathrm{w}}$ and depths are given for historical earthquakes (see Traversa et al. (2017) for uncertainties computation details), together with uncertainties in relation to $\mathrm{M}_{\mathrm{w}}$ estimates for instrumental events (coming from (Cara et al. 2017). Historical earthquakes seismological parameters (AD463-1965) are only provided within France boundaries. This does extend $40 \mathrm{~km}$ beyond the French border in order to take into account uncertainty in the SISFRANCE epicenter location and to limit events to those with a high degree of confidence in their computed $\mathrm{M}_{\mathrm{w}}$ and depth. In the same time, SiHex events are only 
provided within France boundaries plus a buffer of $20 \mathrm{~km}$, mainly due to the fact that SiHex project is not authoritative on data located beyond, except within the exclusive economic zone at sea (ZEE).

Acknowledgements SIGMA studies on historical seismicity have benefited from the discussions and suggestions provided by members of the SIGMA scientific committee, and also by participants to the SIGMA catalogue working group. Thank you also to the EDF SISFRANCE partners, IRSN and BRGM, for their collaboration in the SISFRANCE project over the last 40 years. We would like to thank the SiHex teams for their work in producing the SiHex instrumental catalogue, and also to thank the data providers and seismological observatories for collecting and making available earthquakes data. A particular acknowledgement of the members of the Dieudonné Laboratory (Nice-Sophia Antipolis University) we worked and discussed with at the beginning of the project. Thank to Paul for reviewing and improving the English.

Open Access This article is distributed under the terms of the Creative Commons Attribution 4.0 International License (http://creativecommons.org/licenses/by/4.0/), which permits unrestricted use, distribution, and reproduction in any medium, provided you give appropriate credit to the original author(s) and the source, provide a link to the Creative Commons license, and indicate if changes were made.

\section{References}

Ambraseys N (1985) Magnitude assessment of northwestern European earthquakes. Earthq Eng Struct Dyn $13: 307-320$

Bakun WH (2006) Estimating locations and magnitudes of earthquakes in southern California from modified Mercalli intensities. Bull Seismol Soc Am 96:1278-1295

Bakun WH, Scotti O (2006) Regional intensity attenuation models for France and the estimation of magnitude and location of historical earthquakes. Geophys J Int 164:596-610. doi:10.1111/j.1365-246X. 2005.02808.x

Bakun WH, Wentworth CM (1997) Estimating earthquake location and magnitude from seismic intensity data. Bull Seismol Soc Am 87:1502-1521

Baroux E, Bethoux N, Bellier O (2001) Analysis of the stress field in southeastern France from earthquake focal mechanisms. Geophys J Int 145:336-348

Baumont D, Scotti O (2011) The French parametric earthquake catalogue (FPEC) based on the best events of the SisFrance macroseismic database-version 1.1. Rapport IRSN/DEI/2011-012

Baumont D, Manchuel K, Traversa P, Baumont D, Manchuel K, Traversa P, Durouchoux C, Nayman E, Ameri G (submitted) Intensity attenuation models calibrated in Mw for metropolitan France. Bull Earthq Eng

Beauval C, Yepes H, Bakun WH et al (2010) Locations and magnitudes of historical earthquakes in the Sierra of Ecuador (1587-1996). Geophys J Int 181:1613-1633

Benjumea J, Cara M, Rivera L (2015) Study of instrumented earthquakes that occured during the first part of the 20th century (1905-1962). SIGMA deliverable D1-129

Braunmiller J, Deichmann N, Giardini D et al (2005) Homogeneous moment-magnitude calibration in Switzerland. Bull Seismol Soc Am 95:58-74. doi:10.1785/0120030245

Camelbeeck T (1985) Recent seismicity in Hainaut—scaling laws from the seismological stations in Belgium and Luxemburg. In: Melchior PJ (ed) Seismic activity in Western Europe, vol 144. Springer, Dordrecht, pp 109-126

Cara M, Cansi Y, Schlupp A et al (2015) Si-Hex: a new catalogue of instrumental seismicity for metropolitan France. Bull Soc Géol Fr 186:3-19. doi:10.2113/qssqfbull.186.1.3

Cara M, Denieul M, Sèbe O et al (2017) Magnitude Mw in metropolitan France. J Seismol 21:551-565. doi:10.1007/s10950-016-9617-1

Cecic I, Musson RMW, Stucchi M (1996) Do seismologists agree upon epicenter determination from macroseismic data? A survey of ESC working group "macroseismology". Ann Geophys 39(5): 1013-1027

Cushing EM, Bellier O, Nechtschein S et al (2008) A multidisciplinary study of a slow-slipping fault for seismic hazard assessment: the example of the Middle Durance Fault (SE France). Geophys J Int 172:1163-1178. doi:10.1111/j.1365-246X.2007.03683.x

Denieul M (2014) Moment sismique et coda d'ondes crustales. Ph.D., Université de Strasbourg 
Denieul M, Sèbe O, Cara M, Cansi Y (2015) Mw estimation from crustal coda waves recorded on analog seismograms. Bull Seismol Soc Am 105:831-849. doi:10.1785/0120140226

Dezes P, Schmid SM, Ziegler PA (2004) Evolution of the European Cenozoic Rift System: interaction of the Alpine and Pyrenean orogens with their foreland lithosphere. Tectonophysics 389:1-33

Gasperini P, Vannucci G, Tripone D, Boschi E (2010) The location and sizing of historical earthquakes using the attenuation of macroseismic intensity with distance. Bull Seismol Soc Am 100:2035-2066

Godano M, Larroque C, Bertrand E et al (2013) The October-November 2010 earthquake swarm near Sampeyre (Piedmont Region, Italy): a complex multicluster sequence. Tectonophysics 608:97-111

Gomez-Capera AA, Rovida A, Gasperini P et al (2015) The determination of earthquake location and magnitude from macroseismic data in Europe. Bull Earthq Eng 13:1249-1280. doi:10.1007/s10518014-9672-3

Grünthal G, Wahlström R (2012) The European-Mediterranean Earthquake Catalogue (EMEC) for the last millennium. J Seismol 16(3):535-570

Grünthal G, Wahlström R, Stromeyer D (2009) The unified catalogue of earthquakes in central, northern, and northwestern Europe (CENEC)-updated and expanded to the last millenium. J Seismol 13:517-541. doi:10.1007/s10950-008-9144-9

Grünthal G, Wahlström R, Stromeyer D (2013) The SHARE European Earthquake Catalogue (SHEEC) for the time period 1900-2006 and its comparison to the European-Mediterranean Earthquake Catalogue (EMEC). J Seismol 17:1339-1344. doi:10.1007/s10950-013-9379-y

Hinzen KG, Oemish M (2001) Location and magnitude from seismic intensity data of recent and historic earthquakes in the Northern Rhine area, Central Europe. Bull Seismol Soc Am 91:40-56

Kövesligethy R (1907) Seismischer Stärkegrad und Intensität der Beben. Gerlands Beitr Geoph 8:24-103

Lambert J, Montfort-Climent D, Bouc O (2015) Catalogue of isoseismal areas for XXth century french historical earthquakes (Io > VI). BRGM report BRGM/RC-66444-FR

Levret A, Backes JC, Cushing M (1994) Atlas of macroseismic maps for French earthquakes with their principal characteristics. Nat Hazards 10:19-46

Locati M, Camassi R, Stucchi M (2011) DBMI11, la versione 2011 del Database Macrosismico Italiano. Milano, Bologna, http://emidius.mi.ingv.it/DBMI11. doi:10.6092/INGV.IT-DBMI11

Mayor J, Traversa P, Calvet M, Margerin L (2017) Tomography of crustal seismic attenuation in Metropolitan France: implications for seismicity analysis. Bull Earthq Eng. doi:10.1007/s10518-0170124-8

Medvedev SP, Sponheuer W, Karnik V (1967) Seismic intensity scale version 1964. Inst. Geody. Publ., Jena, p 48

Musson RMW (1996) Determination of parameters for historical British earthquakes. Ann Geofis 39:1041-1047

Musson RMW, Cecic I (2012) Intensity and intensity scales. In: Bormann P (ed) New manual of seismological observatory practice 2 (NMSOP-2). Deutsches GeoForschungsZentrum GFZ, Potsdam, pp 1-41

Nocquet J-M, Calais E (2004) Geodetic measurements of crustal deformation in the Western Mediterranean and Europe. Pure Appl Geophys 161:661-681

Rovida A, Camassi R, Gasperini P, Stucchi M (2011) CPTI11, la versione 2011 del Catalogo Parametrico dei Terremoti Italiani Istituto Nazionale di Geofisica et Vulcanologia, Milano, Bologna, http://emidius. mi.ingv.it/CPTI. doi:10.6092/INGV.IT-CPTI11

Scordilis EM (2006) Empirical global relations converting Ms to mb to moment magnitude. J Seismol 10:225-236. doi:10.1007/s10950-006-9012-4

SISFRANCE www.sisfrance.net.

Sponheuer W (1960) Methoden zur Herdtiefenbesttimmung in der Makroseismik, Freiberger Forschungsthefte

Stucchi M, Rovida A, Gomez-Capera AA et al (2012) The SHARE European earthquake catalogue (SHEEC) 1000-1899. J Seismol. doi:10.1007/s10950-012-9335-2

Tarantola A (2005) Inverse problem theroy and methods for model parameter estimation. Society for Industrial and Applied Mathematics, Philadelphia

Thouvenot F, Jenatton L, Gratier JP (2009) 200-m-deep earthquake swarm in Tricastin (lower Rhône Valley, France) accounts for noisy seismicity over past centuries. Terra Nova 21:203-210

Traversa P, Manchuel K, Mayor J (2014) On the use of cross-border macroseismic data to improve the estimation of past earthquakes seismological parameters. In: 2ECEES meeting, Istanbul, Turkey, vol 12

Traversa P, Baumont D, Manchuel K, Nayman E (2017) Exploration tree approach to estimate historical earthquakes $\mathrm{M}_{\mathrm{w}}$ and depth, test cases from the French past seismicity. Bull Earthq Eng. doi:10.1007/ s10518-017-0178-7

Walpersdorf A, Baize S, Calais E et al (2006) Deformation in the Jura Mountains (France): First results from semi-permanent GPS measurements. Earth Planet Sci Lett 245:365-372 